\title{
Differences in Attitudes towards Immigration between Australia and Germany: The Role of Immigration Policy
}

\author{
Philipp Ueffing, Francisco Rowe, Clara H. Mulder
}

\begin{abstract}
This paper investigates the connection between national immigration policy and a society's attitudes towards immigration. It argues that a country's immigration policy framework plays an important role in the formation of attitudes towards immigration by shaping the local national context of the receiving country. It examines the influence of a country's immigration policy framework by contrasting two countries - Australia and Germany - that developed remarkably different immigration policies in response to large immigration movements during the postwar period. We explore attitudes towards immigration on four dimensions: (1) the national economy, (2) the labour market, (3) the national culture, and (4) the level of immigrant influx. The analyses reveal three main findings. First, people in Australia tend to display more positive attitudes towards immigration than in Germany. Second, in both countries, attitudes towards immigration tend to be influenced in a similar way by an individual's socio-economic background and feelings of national identity (in the form of nationalism and patriotism). Third, immigration policy represents a strong indicator of attitudes towards immigration. We found that the planned integrative immigration policy in Australia supports the formation of more positive attitudes towards immigration by influencing people's perception on the economic and socio-cultural impacts of immigration.
\end{abstract}

Keywords: Immigration · Policy · Attitudes · Australia - Germany

\section{Introduction}

With immigration increasing in size and complexity, there has been lively public debate about the impacts of immigration in western countries (Castles/Miller 2008). On the one hand, immigration is considered a welcome source of labour and cultural diversity, as a foundation for new ideas and a strategy for addressing contemporary demographic processes such as population decline, decreasing fertility levels and population ageing. On the other hand, immigration raises concerns about detrimen- 
tal effects on national welfare systems, increasing job competition and undermining national culture (Joppke 1999). These conflicting views vary within and across countries and result in diverse attitudes towards immigration among local populations.

Previous research has investigated differences in attitudes towards immigration from micro and macro perspectives. By using a micro approach, individual characteristics have been found to exert a strong influence on attitudes towards immigration. Residing in an urban area, high educational attainment and being born in a foreign country have all shown to increase the tendency to hold positive attitudes towards immigration. However, cross-country differences in the importance of these variables are less clear (Davidov/Meuleman 2012). From a macro perspective, studies have sought to explain attitudes towards immigration based on the national socio-economic conditions of countries by using aggregate economic and social variables (e.g. gross domestic product, the proportion of foreign-born members of a country's population, or the unemployment rate). While evidence for a link between economic conditions and the size of the immigrant population has been found (Mayda 2006; O'Rourke/Sinnott 2006), the majority of these studies has either established no relationship (Brenner/Fertig 2006; Card et al. 2005; Sides/Citrin 2007), or only weak effects (Meuleman et al. 2009; Rustenbach 2010) of these macro socio-economic variables on attitudes towards immigration. Thus, rather than observable socio-economic country characteristics, less easily measurable factors, such as countries' migration histories have been argued to underpin cross-country differences in attitudes towards immigration (Brenner/Fertig 2006).

However, these factors have received little attention in prior work. The role of the national socio-political and institutional contexts within which attitudes towards immigration are formed are considered as important factors to better understand cross-national differences in these attitudes (Ceobanu/Escande/l 2010).

Based on this argument, we explore the role of a country's immigration policy framework as an indicator of cross-national differences in attitudes towards immigration. In other words, attitudes towards immigration are argued to reflect a countries' immigration policy. Bauer et al. (2001) suggest that an immigration policy focusing on skilled migrants does a better job at assimilating immigrants into the labour market, which in turn results in more positive views on immigration. Schlueter et al. (2013) demonstrate that permissive immigrant integration policies improve attitudes towards immigrants by diminishing perceptions of immigration as a threat to the interests of the native population.

To explore the relationship between immigration policy and attitudes towards immigration, we analyse differences in attitudes towards immigration in Australia and Germany using data from the 2003 International Social Survey Program (ISSP). The methodological approach of this paper differs from previous research. Rather than using a micro-level analysis to identify determinants of individual attitudes or a macro-level analysis to detect cross-country differences, we integrate both analytical approaches by examining the differences in attitudes towards immigration in two countries in a framework that considers the influence of national immigration policy. Australia and Germany offer a unique setting to explore the influence of immigration policy on attitudes toward immigration, as these countries represented 
“opposite poles on the migration spectrum" (Castles 2008: 1) from the early 1970s until the onset of substantial immigration policy reforms in Germany in 2005. The timing of the ISSP survey in 2003 allows us to examine attitudinal differences between Germany and Australia at the end of the long-standing contrast in policy frameworks. This is important, as attitudes towards immigration are shaped over time (Card et al. 2005) through "legacies of past migrations and migration policies" (Godenau et al. 2012). As immigration is perceived to impact the social, cultural and economic environments of a country, we capture differences in attitudes towards immigration emerging from these different perspectives. The question we seek to address is: How are the contrasting immigration policy frameworks established in Australia and Germany related to cross-country differences in attitudes towards immigration?

\section{Theoretical framework}

Immigration policy is reflected in attitudes towards immigration (Bauer et al. 2001; Schlueter et al. 2013). Controlling for the size of the migrant population, economic conditions and political-ideological circumstances, Schlueter et al. (2013) identified immigration policy as a key contextual factor for understanding cross-country differences in attitudes towards immigration. However, the relationship between immigration policy and attitudes towards immigration is not straightforward. The causal direction of the link between policy and attitudes likely goes both ways. Bauer et al. (2001) point out that "policy and sentiments recursively influence each other and the direction of causality is hard to disentangle" (2001: 20). On the one hand, politicians and policymakers respond to what they think the general public perceives as the right direction of policy. On the other hand, immigration policy shapes attitudes towards immigration by influencing people's perceptions of the impact of immigration (Schlueter et al. 2013). These perceptions are formed based on the "belief" in the impact of immigration, rather than on real effects of immigration (Card et al. 2005; Gang et al. 2002). Hence, immigration policy is related to attitudes towards immigration, which are in turn influenced by the perceived consequences of immigration.

Immigration policy plays a role in the formation of attitudes towards immigration through the regulation and management of the influx of immigrants and their settlement. Immigration policy channels the ethnic and skill composition of countries' immigrant flows, designs the service and support for those who have settled, and manages the ethno-cultural changes of national populations resulting from immigration (Jupp 2007). These different targets of immigration policy link more closely to specific perceptions of the local population on immigration and particular ties can be constituted. The manner in which immigration is regulated, i.e. through a designed immigration programme, is associated with people's views on the size of the immigrant inflow. At the same time, immigration policies based on economic considerations relate to how people perceive the impact of immigration on the economy or the labour market, while policies concerning the incorporation of im- 
migrants and their distinctive cultures into society influence the perception of the socio-cultural impact of immigration.

Hence, to examine the relationship between policy and attitudes towards immigration, four dimensions of attitudes corresponding to the different perceptions on impacts of immigration are defined: (1) the national economy, (2) the labour market, (3) the national culture, and (4) the level of immigrant influx. This approach differs from previous studies, which have focussed on understanding attitudes towards one of these four dimensions (the level of immigrant influx). Meanwhile, attitudes towards the economic and cultural consequences of immigration for a country have only been examined as factors influencing attitudes towards the level of immigration (Malchow-Møller et al. 2009). In this paper, we explore the influence of immigration policy across these four dimensions to capture distinct associations between immigration policy and attitudes towards immigration.

\subsection{Australia and Germany: Opposing immigration policies}

Australia and Germany have displayed stark differences in their immigration policies since the 1970s, when opposite policy frameworks emerged from different responses to mass immigration movements following World War II (Castles 2008). Concerning the period in Germany prior to reunification in 1990, the focus is on developments in West Germany. After the end of the German Democratic Republic, East Germany was incorporated into the Federal Republic of Germany with all its cultural, social, and political institutions. As a result, concerning attitudes towards immigrants, stereotypes held by West Germans were "adopted" by the East German population (Meier-Braun 2002). Furthermore, Germany has begun to make significant changes to its immigration policy since the ratification of a new immigration act in 2005. However, our analysis focusses on policy developments preceding the ISSP survey in 2003.

Australia has been following an immigration policy of planned immigration that aims at increasing the country's population and stimulating economic growth. Under a multicultural principle, the country operates an immigration programme that focusses on skilled immigration. Integrative measures assist immigrants' settlement process while also supporting the practice of their cultural customs and traditions (Birrell 2009; Hugo 2004, 2009; Jupp 2007; Markus et al. 2009). The country has achieved considerable "capacity to formulate, develop, introduce and operate sound and effective policy" (Hugo 2004: 3).

In contrast to Australia, Germany did not establish an explicit immigration policy. Despite a significant and growing immigrant population, German policymakers have failed to develop consistent migration and integration legislation. Throughout the second half of the $20^{\text {th }}$ century, the central theme of Germany's immigration policy has been the perception that Germany is not "a country of immigration" and immigration has been "uncontrolled" in the past (Zimmermann et al. 2007). Policymakers have been operating under a narrative portraying Germany as a culturally homogenous country uninterested in permanent immigrants (Joppke 1999; MeierBraun 2002; Meyers 2007; Suessmuth 2001; Zimmermann et al. 2007). 


\subsection{Policy and attitudinal differences}

In this study, we expect the opposing policy paradigms of Australia and Germany to result in differences in attitudes towards immigration between the countries' populations. Operating under a multicultural principle, Australia's planned immigration policy is thought to be associated with greater acceptance of immigration and its socio-cultural and economic consequences than in Germany, where, instead, policy focussed on the overall restriction and reduction of immigration. Hence, we expect more positive attitudes in Australia than in Germany towards immigrant influx and the impact of immigration on the economy, the labour market, and national culture. With regard to the economic impacts of immigration, more positive attitudes are expected in Australia for two reasons. First, the immigration policy of Australia is economically driven. The government specifically defines its skilled immigration programme as "designed to target migrants who have skills or outstanding abilities that will contribute to the Australian economy" (DIMA 2010). Thus, Australia's immigration policy supports the perception that immigration benefits the national economy. Second, the country's immigration policy mitigates the perceived threat of increased labour market competition due to immigration. Australia has increasingly focussed on a skilled immigration programme based on labour force shortages. Governments have continuously involved unions and employers' associations in the labour market evaluation process identifying these shortages. By including non-governmental organisations, Australian policymakers have mediated public opposition and eased fears about increased job competition resulting from immigration (Jupp 2007).

In contrast, we expect less favourable sentiments towards the economic impact of immigration in Germany. A comprehensive economy-oriented migration programme has not been instituted in Germany, despite advocacy for skilled immigration from the German employer lobby. The absence of such a programme is coupled with a different political response to the perceived threat of increased competition on the labour market through immigration. German policymakers, for example, stopped a large recruitment programme for foreign labour in 1973 due to an increase in unemployment, although there was still a demand for migrant workers in specific sectors of the industry (Joppke 1999). In contrast to Australia, there has not been a consensus between major political parties on the economic benefits of immigration for the country.

In combination with the more favourable perceptions of the economic impacts of immigration in Australia, the country's multicultural policy is also expected to be associated with more positive attitudes towards the cultural impact of immigration than in Germany. Under the multicultural paradigm, Australian policymakers eliminated national origin as a selection criterion for immigration, installed support systems for migrants to maintain their cultural ties, and implemented a liberal citizenship law that allows migrants to naturalise within a relatively short period of time while keeping multiple citizenships.

German immigration policy is thought to relate to less favourable attitudes towards such cultural impacts, as policy has been developed based upon the view 
of Germany as a culturally homogenous country, defined by a shared language, tradition, and descent (Levy 2002). This is particularly evident in German citizenship law. While resettlers are granted citizenship if considered "ethnically German", naturalisation for immigrants without German descent is a long and difficult process. In fact, Germany did not depart from its ethnic concept of nationality until the late $20^{\text {th }}$ century. Naturalisation became easier for immigrants not considered "ethnically German" and their German-born children after a reform of the citizenship law in 2000 (Zimmermann et al. 2007).

While the immigration policy framework provides some of the context within which attitudes towards immigration are formed, these behavioural responses depend in part on individuals' positions in various domains in life. Hence, after discussing alternative contextual factors that might influence attitudes towards immigration in Australia and Germany in section 2.3, section 2.4 will review personal characteristics that potentially influence attitudes towards immigration.

\subsection{Other contextual factors}

Besides immigration policy, other country-level structural conditions have been suggested to influence attitudes towards immigration and might explain differences between Australia and Germany. The size of migrant populations, fluctuations in the level of immigration, economic conditions, media coverage and the national discourse on immigration and political-ideological traditions have been linked to the formation of attitudes towards immigration within countries (Ceobanu/Escandel/ 2010). Overall, the presence of migrants is higher in Australia than in Germany. Around the time of the ISSP survey in 2005, both countries were home to some of the largest immigrant populations in the world, with 10.1 million migrants in Germany and 4.1 million migrants in Australia (UNDESA 2006). This corresponds to 12 percent of the German and 23 percent of the Australian population. Furthermore, the economic climates in the two countries were different at the turn of the century. In the decade preceding the survey, Australia experienced a period of strong economic growth with an annual GDP growth rate of around 4 percent between 1995 and 2004, while economic growth in Germany was much weaker (The World Bank 2015). However, there is a lack of consistent evidence for the size of migrant population and the state of the economy influencing attitudes towards immigration (Sides/ Citrin 2007).

\subsection{The influence of individual characteristics}

A set of individual, personal characteristics has been shown to influence attitudes towards immigration. Individual socio-economic background and feelings of national identity and belonging have consistently been found to impact the formation of such attitudes (Ceobanu/Escande// 2010).

Based on economic self-interest, people generally tend to oppose immigration when they perceive immigrants as competitors for resources (Card et al. 2005; Mayda 2006; O'Rourke/Sinnott 2006; Scheve/Slaughter 2001; Sides/Citrin 2007). 
Since immigrants are predominantly considered to be less qualified, lower skilled persons are more likely than higher skilled persons to perceive migrants as competitors on the labour market in the context of developed countries. Hence, people in low-skill professions hold more negative attitudes concerning the labour market impact of immigration, and prefer lower numbers of immigrants (Mayda 2006; Scheve/Slaughter 2001).

Place of residence and migration history represent two key factors influencing personal attitudes towards immigration. Living in an urban area, and being an immigrant or descendant of immigrants are related to favourable attitudes (Bauer et al. 2001; Hainmueller/Hiscox 2007; Malchow-Møller et al. 2009; Mayda 2006; O'Rourke/Sinnott 2006). The exposure to the cultural heterogeneity of cities is suggested to drive more positive attitudes (Hayes/Dowds 2006; Wilson 1991). Stronger pro-immigration sentiments among persons with a migration background has been linked to self-identification with immigrants (Hayes/Dowds 2006).

Furthermore, increasing age has been correlated with negative sentiments on immigration (Bauer et al. 2001; Brenner/Fertig 2006; Mayda 2006; Scheve/Slaughter 2001). Older people tend to be more conservative and sceptical about change, and thus hold less positive attitudes towards immigration. Effects of gender are less clear. Mayda (2006), for example, demonstrated that females were more opposed to immigration, while Bauer et al. (2001) found males to have more negative sentiments towards immigration. At the same time, Brenner and Fertig (2006) did not find any relationship between gender and attitudes towards immigration.

Feelings of national belonging and identity also influence attitudes towards immigration (Card et al. 2005; Davidov et al. 2008; Sides/Citrin 2007). Sides and Citrin (2007: 479) argue that "beliefs about the nation and its cultural make-up" are particularly important for the formation of attitudes towards immigration. Persons with strong feelings of national belonging have been commonly found to be less open to immigration (O'Rourke/Sinnott 2006; Sides/Citrin 2007). Recent work by Jeong (2013) investigated different types of national feelings and found that feelings of national superiority provoke negative attitudes towards immigration, while feelings of national pride led to more positive attitudes towards immigration.

While the relationship between personal characteristics and attitudes towards immigration is grounded, differences in the influence of personal characteristics on attitudes across countries are left largely unexplained (Brenner/Fertig 2006; Davidov et al. 2008; Sides/Citrin 2007). The contrasting policies in Australia and Germany are expected to relate to these personal characteristics. Specifically, the attitudinal difference between skill levels is expected to be less pronounced in Australia, as the Australian immigration policy has increasingly focused on skilled immigration. Highly skilled workers in Australia might be more likely than their German counterparts to perceive immigration as an increase in labour market competition. In contrast, German policy makers have largely disregarded skill-oriented immigration, and migrants have mainly arrived through family reunification, immigration of ethnic Germans from the successor states of the former Soviet Union and asylum requests. Hence, Australia's skills-based policy is thought to evoke a relatively strong perception of immigrants as competitors for jobs requiring higher qualifications. 


\section{Data and measures}

\subsection{International Social Survey Programme Data}

We use nationally representative survey data of the Australian and German population aged 18 and older from the 2003 National Identity (NI) module, maintained by the International Social Survey Programme (ISSP). To enable cross-national comparability, the ISSP works in collaboration with governments to develop standardised topic-specific questions that are integrated into national surveys. For the $2003 \mathrm{NI}$ ISSP module, Australia and Germany incorporated a set of questions on national identity in the Australian Survey of Social Attitudes (AuSSA) and German General Social Survey (ALLBUS), respectively. Data collected using these questions offer information on attitudes towards immigration, national identity and belonging, as well as the socio-demographic characteristics of respondents. We focused the analysis on 2,130 individual records for Australia and 1,198 for Germany. These records comprise the cases for which information on relevant variables used in our analysis was available.

\subsection{Measures of attitudes towards immigration}

Using the ISSP data, we constructed four indicators of attitudes towards immigration for Australia and Germany. As discussed in Section 2, we use four alternative approaches to measure individuals' attitudes towards immigration: people's perceptions of the impact of immigration on (1) the national economy, (2) the labour market, and (3) culture, and (4) people's preferred level of immigration influx. Data on these four dimensions were collected in the ISSP module on a five-point ordinal scale, representing the attitudes of the host population towards immigration. Measurement comparability was assessed by comparing response distributions in Australia and Germany and other English-speaking (Great Britain, USA) and Germanspeaking (Austria, part of Swiss sample) countries available in the ISSP dataset. While cross-country differences in respondents' understanding of survey questions have been found for some variables in ISSP modules due to language particularities (Harkness et al. 2004; Scholz et al. 2005), systematic differences between the two language groups were not apparent for the four measures of attitudes towards immigration, supporting measurement comparability. We then recoded the five-point ordinal data to create four binary variables with one indicating positive attitudes towards immigration (for influx: a preference for increasing levels) and zero otherwise (Table 1). The "neutral" category, coded as zero, accounted for about a quarter of responses across the four measures (Response distributions over the original five categories are shown in appendix Table A2). The dichotomisation of the response categories was necessary for technical reasons (see Methodology section). 
Tab. 1: Construction of the four measures of attitudes towards immigration from ISSP data

\begin{tabular}{|c|c|c|}
\hline Measures & ISSP data questions and scheme codes & Binary indicator (= ISSP data codes) \\
\hline \multirow[t]{6}{*}{ Economy } & $\begin{array}{l}\text { Immigrants are generally good for } \\
\text { [Country's] economy: }\end{array}$ & $\begin{array}{l}\text { 1: Positive attitudes toward } \\
\text { immigration ( }=4 \text { and } 5)\end{array}$ \\
\hline & 1. Strongly disagree & $0:$ Otherwise $(=1,2$ and 3$)$ \\
\hline & 2. Disagree & \\
\hline & 3. Neutral & \\
\hline & 4. Agree & \\
\hline & 5. Strongly agree & \\
\hline \multirow[t]{6}{*}{ Labour Market } & $\begin{array}{l}\text { Immigrants take jobs away from people } \\
\text { who were born in [Country]: }\end{array}$ & $\begin{array}{l}\text { 1: Positive attitudes toward } \\
\text { immigration (= } 1 \text { and } 2)\end{array}$ \\
\hline & 1. Strongly disagree & $0:$ Otherwise $(=3,4$ and 5$)$ \\
\hline & 2. Disagree & \\
\hline & 3. Neutral & \\
\hline & 4. Agree & \\
\hline & 5. Strongly agree & \\
\hline \multirow[t]{6}{*}{ Culture } & $\begin{array}{l}\text { Immigrants improve [Country nationality] } \\
\text { society by bringing in new ideas and } \\
\text { cultures: }\end{array}$ & $\begin{array}{l}\text { 1: Positive attitudes toward } \\
\text { immigration }(=4 \text { and } 5) \\
0 \text { : Otherwise }(=1,2 \text { and } 3)\end{array}$ \\
\hline & 1. Strongly disagree & \\
\hline & 2. Disagree & \\
\hline & 3. Neutral & \\
\hline & 4. Agree & \\
\hline & 5. Strongly agree & \\
\hline \multirow[t]{6}{*}{ Influx } & $\begin{array}{l}\text { Do you think the number of immigrants to } \\
\text { [Country] nowadays should be ... }\end{array}$ & $\begin{array}{l}\text { 1: Positive attitudes toward } \\
\text { immigration (= } 1 \text { and } 2 \text { ) }\end{array}$ \\
\hline & 1. Increased a lot & $0:$ Otherwise $(=3,4$ and 5$)$ \\
\hline & 2. Increased & \\
\hline & 3. Remain the same & \\
\hline & 4. Reduced & \\
\hline & 5. Reduced a lot & \\
\hline
\end{tabular}

\section{$4 \quad$ Methodology}

The methodological strategy involves a two-step approach. First, we seek to establish the extent of the difference in attitudes towards immigration between Australia and Germany by employing a Chi-square test of proportions. By using this test, we evaluate the null hypothesis of equality of proportions of positive attitudes towards immigration between Australia and Germany, concerning each of the dimensions in Table 1. The outcomes of this test are a Chi-square statistic and a p-value. These indicators are then used to evaluate the statistical significance of the difference in attitudes towards immigration between the two countries. P-values below 1 percent 
provide statistical evidence for rejecting the null hypothesis of equality, suggesting that there are significant differences in attitudes towards immigration between Australia and Germany. We performed Fisher's exact tests, which are appropriate for small sample sizes (Fienberg 1980). The results provided by these tests were consistent with those from standard Chi-square tests.

Second, we seek to determine the key factors leading to the difference in attitudes towards immigration between Australia and Germany. To this end, we estimate probit regression models per country, the results of which are used to perform a Blinder-Oaxaca type decomposition analysis. We argue that cross-national differences in attitudes towards immigration can be the result of differences in two broader components: (1) population composition (composition effects) and (2) the perceived impacts of immigration (behavioural effects). Composition effects are related to how cross-national differences in the distribution of individual characteristics impact the difference in attitudes towards immigration between countries. For instance, highly-skilled people are more likely to view immigration positively. Hence, countries with a larger share of highly-skilled persons can be expected to have more positive attitudes. Behavioural effects relate to how cross-national differences in behavioural responses influence differences in attitudes towards immigration between countries. Differences between Australia and Germany in behavioural responses to immigration are argued to reflect the effect of differences in the established immigration policy frameworks of the two countries. The long-standing existence of a coherent, multicultural policy framework regulating immigration settlement and intake in Australia is expected to have contributed to the formation of positive attitudes towards immigration.

In the regression model, the probability of a person (i) displaying positive attitudes towards immigration is considered as a function of a set of individual determinants $(X)$ and associated parameters $(\beta)$ :

$$
P_{i}=F\left(X_{i} \beta\right)
$$

The difference between Australians $(A)$ and Germans $^{1}(G)$ in the average probability of having pro-immigration attitudes $\left(\bar{P}_{A}-\bar{P}_{G}\right)$ can be decomposed into two components, representing composition and behavioural effects:

$$
\bar{P}_{A}-\bar{P}_{G}=\left(\overline{F\left(X_{A} \beta_{G}\right)}-\overline{F\left(X_{G} \beta_{G}\right)}\right)+\left(\overline{F\left(X_{A} \beta_{A}\right)}-\overline{F\left(X_{A} \beta_{G}\right)}\right)
$$

Equation (2) provides estimates of the overall compositional and behavioural effects. The first term on the right-hand side of equation (2) accounts for crossnational differences in population composition (i.e. composition effects), while the second term accounts for cross-national differences in coefficients (i.e. behavioural effects). These terms can then be used to determine the relative contribution of each explanatory variable associated to the two sets of effects.

\footnotetext{
1 We refer to "Australians" and "Germans" to describe residents of these countries.
} 
To implement the decomposition analysis, we applied binary probit regression models following the methodology of Yun (2008). Eight regression models were run, one per country for each of our four measures of attitudes towards immigration. Ideally, we would have preserved the original ordered categorical variable from the ISSP, and employed ordered probit or logit regression models rather than binary models to implement the decomposition analysis. However, as Madden (2010: 104) notes, while Oaxaca-Blinder type decompositions can be performed on ordered categorical variables to estimate the overall effects, it is not possible to estimate the individual contribution of each explanatory variable. Although we only report the results from binary regression models, we also conducted decomposition analyses using ordered regression models to estimate the overall compositional and behavioural effects (following Bauer and Sinning (2008)). The results of these analyses were consistent with the results presented in this paper.

Eight sets of independent variables were included in the regression models. These variables were meant to capture the individual influences of age, age squared (to represent the non-linear effect of age), sex, migration background (at least one parent being foreign-born), area of residence (village, town, outer area of a major city, and inner area of a major city), educational attainment (university graduate versus other levels), occupation (elementary, manual, technical, professional, and managerial occupations), nationalism, and patriotism on the probability of displaying pro-immigration attitudes. Age, age squared, nationalism, and patriotism were added to the model as continuous variables, while the remaining variables were categorical. Nationalism and patriotism were constructed as indexes from a set of questions. They describe two distinct concepts of national identity. Nationalism is understood as an uncritical idealisation of the nation and a feeling of superiority over other nations. Patriotism is defined as a feeling of national pride which develops from a conscious evaluation of one's own country, regardless of other nations (Blank/Schmidt 2003; Mummendey et al. 2001). Appendix A1 details the definitions of the independent variables and Table 2 shows their means and percentages.

To evaluate the representativeness of the sample, we compared our data with official census and national survey data on the population composition of Australia and Germany. ${ }^{2}$ Except for the variables of migration background and age, no serious under- or overrepresentations were found and the differences between Australia and Germany were consistent with those found in the population data. Compared to Germany, Australia showed higher shares of people with a university degree, living in major cities; and engaged in professional and managerial occupations. Both countries presented similar sex ratios; and although the sample share of the population with a migration background was underrepresented in both countries, the results were consistent with the fact that this share is larger in Australia than in Germany. Contrary to what could have been expected due to the generally younger

2 Data for the evaluation of our sample were obtained from: Australian Bureau of Statistics (www.abs.gov.au), German Federal Statistical Office (www.destatis.de), International Labour Organisation (www.ilo.org). 
age structure of the Australian population, the mean age of Australians (50) in the ISSP sample turned out to be higher than that of Germans (47). This is likely due to the ISSP survey targeting only the segment of the population aged 18 and older and sampling error (Scholz et al. 2005).

Tab. 2: Percentages and means of explanatory variables

\begin{tabular}{|c|c|c|}
\hline Variable & Australia & Germany \\
\hline \multicolumn{3}{|l|}{ Percentages } \\
\hline \multicolumn{3}{|l|}{ Sex } \\
\hline Male & 46 & 51 \\
\hline Female & 54 & 49 \\
\hline \multicolumn{3}{|l|}{ Migration background } \\
\hline No foreign-born parent & 69 & 87 \\
\hline At least one foreign-born parent & 31 & 13 \\
\hline \multicolumn{3}{|l|}{ Area of residence } \\
\hline Village & 18 & 36 \\
\hline Town & 18 & 32 \\
\hline Outer area of major city & 36 & 12 \\
\hline Inner area of major city & 28 & 20 \\
\hline \multicolumn{3}{|l|}{ University education } \\
\hline No university degree & 78 & 86 \\
\hline University degree & 22 & 14 \\
\hline \multicolumn{3}{|l|}{ Occupation (ISCO88) ${ }^{1}$} \\
\hline Elementary occupations & 8 & 8 \\
\hline Qualified occupations & 46 & 55 \\
\hline Technicians and associate professionals & 13 & 19 \\
\hline Professionals & 20 & 11 \\
\hline Legislators, senior officials and managers & 14 & 7 \\
\hline \multicolumn{3}{|l|}{ Means } \\
\hline Age & 50.46 & 47.08 \\
\hline Nationalism (Range 1 to 5 ) & 4.00 & 3.19 \\
\hline Patriotism (Range 1 to 4 ) & 3.29 & 2.79 \\
\hline
\end{tabular}

1 ISSP uses the 4-digit 1988 International Standard Classification of Occupations (ISCO 88) codes of the International Labour Organisation. We aggregate these to represent the four ISCO 88 skill level categories and the occupation category of legislators, senior officials and managers. Members of armed forces were excluded.

Source: Authors' calculations using data from ISSP 2003 


\section{$5 \quad$ Results}

\subsection{Differences in attitudinal responses between Australia and Germany}

As expected, Australians show more positive attitudes towards immigration than Germans do (Table 3). Across our four dimensions, statistically significant differences in attitudes towards immigration can be observed $(p<0.05)$. The largest disparity between Australia and Germany is found in people's attitudes towards the impact of immigration on the national economy. While 70.5 percent of the Australian sample saw immigration as having positive effects on the national economy, only 26.3 percent of Germans shared this view. Across the remaining three dimensions, the difference in pro-immigration attitudes between Australia and Germany was around 20 percentage points. The gap in positive attitudes towards the impact of immigration on the national economy is especially consistent with the stark contrast between the Australian active immigration programme - organising skilled immigration based on labour market demands - and the German policy that primarily focused on reducing immigration.

Differences in attitudes towards immigration also appear to exist within each country. More than 70 percent of Australians considered the impact of immigration on the national economy and culture as positive. With respect to the labour market impact of immigration, positive attitudes are held by about half of the Australian population. The share of the population preferring increased levels of immigration was less than a quarter. In Germany, the largest proportion of pro-immigration sentiments was found in the dimension of culture (54.4 percent). Positive attitudes towards the impact of immigration on the economy and on the labour market were held by 26.3 and 29.2 percent of the population, respectively. Only 4.5 percent of Germans preferred an increasing influx. The diverse preference patterns underline the multi-dimensional character of attitudes towards immigration. Australians appear to acknowledge the contribution of immigration to the economy and culture, while in the case of Germany, culture is the single dimension where a majority held pro-immigration attitudes. At the same time, regardless of the dimension of attitudes towards immigration, Australians tend to be more positive than Germans.

\subsection{Individual determinants of immigration attitudes}

Table 4 shows the results of the eight regression models. While Nagelkerke's $R$ squared is below 0.2 for seven of the eight models, the log likelihood statistics indicate that full model specifications (containing all the explanatory variables) provide a better fit to the data than models with only an intercept across all models.

Consistent with previous research, the results suggest that people tend to be more positive towards immigration if they have a migration background themselves, live in inner-city areas, earned a university degree, work in higher-skilled jobs and hold less nationalist views. At the same time, gender does not seem to have an effect. 
450 - Philipp Ueffing, Francisco Rowe, Clara H. Mulder

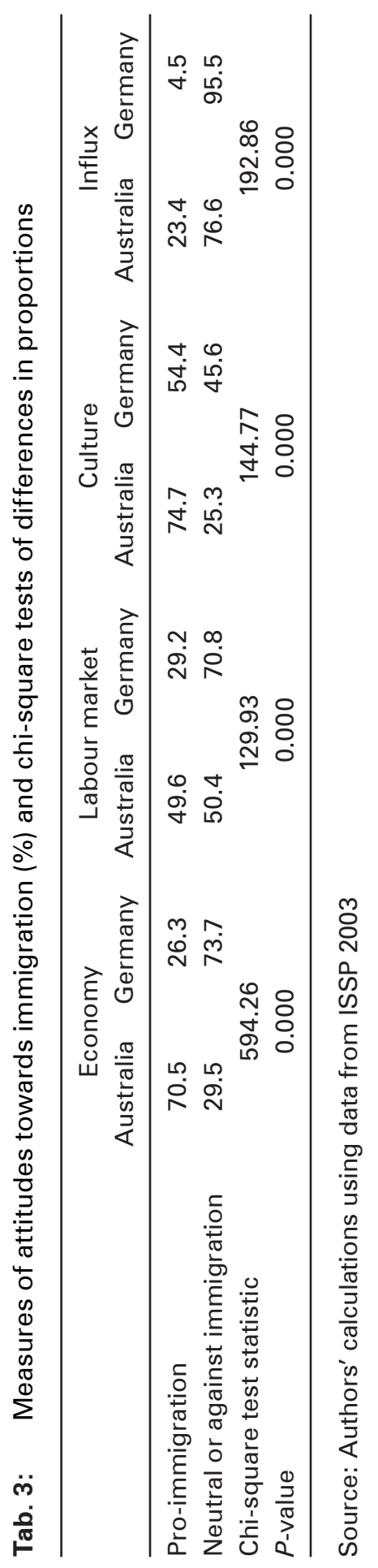




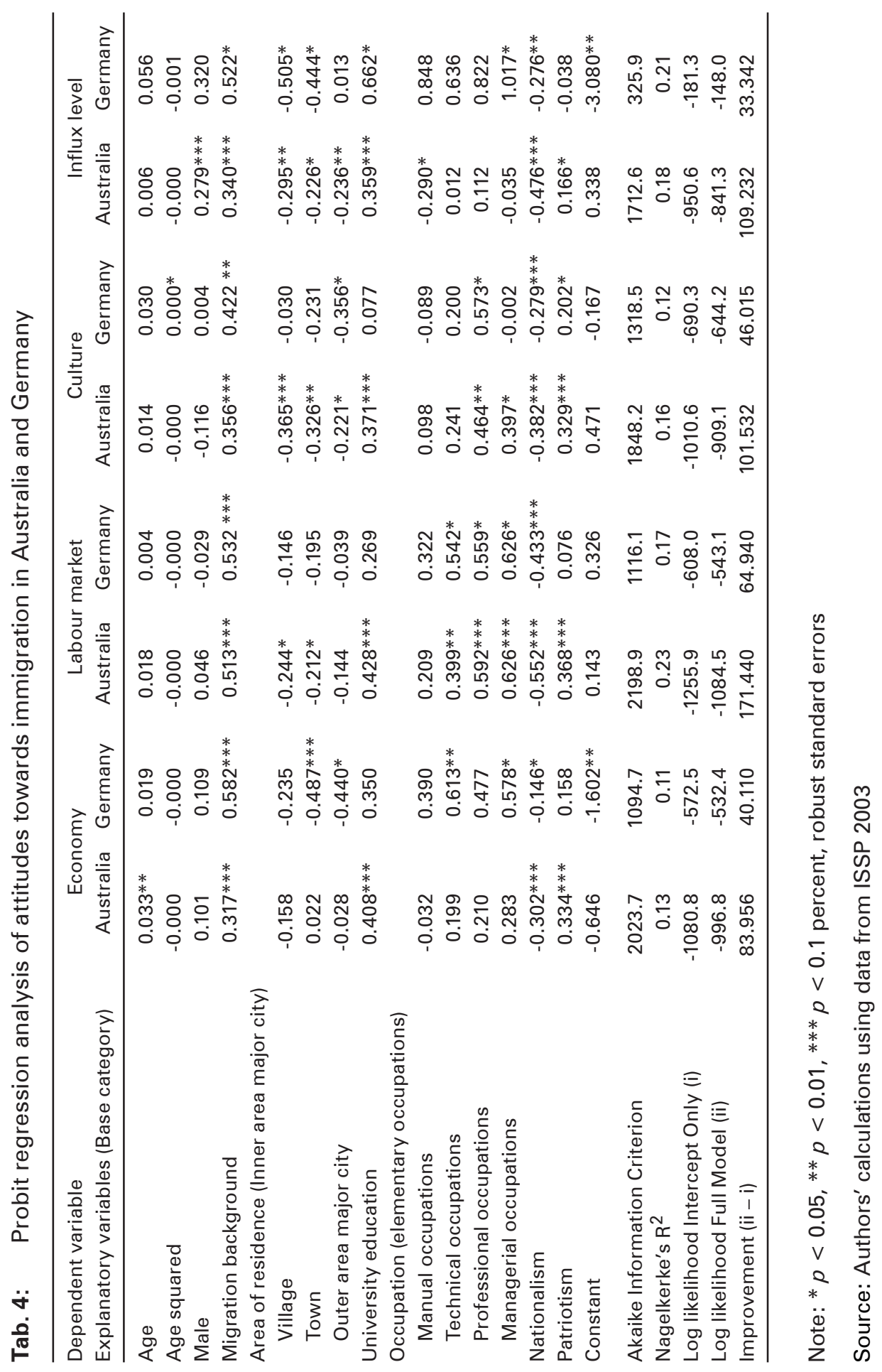


Also in line with recent research, we do not find evidence indicating that the perception of increased labour market competition resulting from immigration leads to negative attitudes towards immigration (Hainmuel/er/Hiscox 2007; O'Connel/ 2011). Evidence for this argument would have been larger differences in the effects associated with skill level, occupation and education, particularly in the labour market dimension. However, we found only small differences between the two countries for occupational effects. It seems that immigration policy is not related to economic self-interest in such a way that a skilled immigration programme evokes a different pattern of sentiments towards immigration across occupational categories between the two countries.

Our results on the effect of age differ from previous findings. Whereas Brenner, Fertig (2006) documented a linear negative effect of age on attitudes towards immigration, our results point to a non-linear influence. While the effect of age is positively associated with the probability of displaying positive attitudes towards immigration at young adult ages, it appears to lessen or to turn negative at older ages. This turning point occurs between the ages of 45 and 65 for the dimensions of labour impact and influx in Australia, and culture and influx in Germany, indicating that people at older ages tend to have less positive attitudes towards immigration.

Supporting recent findings of Jeong (2013), our results show that people with strong patriotic sentiments tend to have more positive attitudes towards immigration. Although this effect is not significant for Germany, the coefficient of patriotism is positive across all eight regression models. The positive influence of patriotism on attitudes towards immigration underlines the ambiguous relationship between feelings of national belonging and identity and attitudes towards immigration shown by Jeong (2013). Devotion to a country appears to be associated with pro-immigration attitudes if it is in the form of patriotism, without the nationalist connotation of superiority over other nations or cultures.

While our results generally point to a similar pattern in the influence of individual characteristics on the probability of holding positive views towards immigration, they also reveal significant differences between Germany and Australia in terms of the magnitude of effects. The major difference is observed in the effects of nationalism and patriotism, which are both stronger in Australia, indicating that notions of belonging and identity in the form of patriotic and nationalist dispositions play a more important role in attitude formation in Australia, although in opposite directions. Australia's multicultural policy might encourage positive attitudes towards immigration among people with patriotic feelings, while strengthening negative sentiment among people with nationalist feelings. Another key difference is the effect of age. While the influence of age on attitudes towards immigration is stronger in Australia than in Germany for the economy and labour-market dimensions, it plays a larger role in Germany in the dimensions of culture and influx. Older people in Australia appear more concerned about the economic impact of immigration, while in Germany, age is a stronger factor regarding immigration numbers and foreign cultures. Furthermore, having a migration background has a stronger positive effect in Germany than it does in Australia. 
Differences in Attitudes towards Immigration between Australia and Germany 453

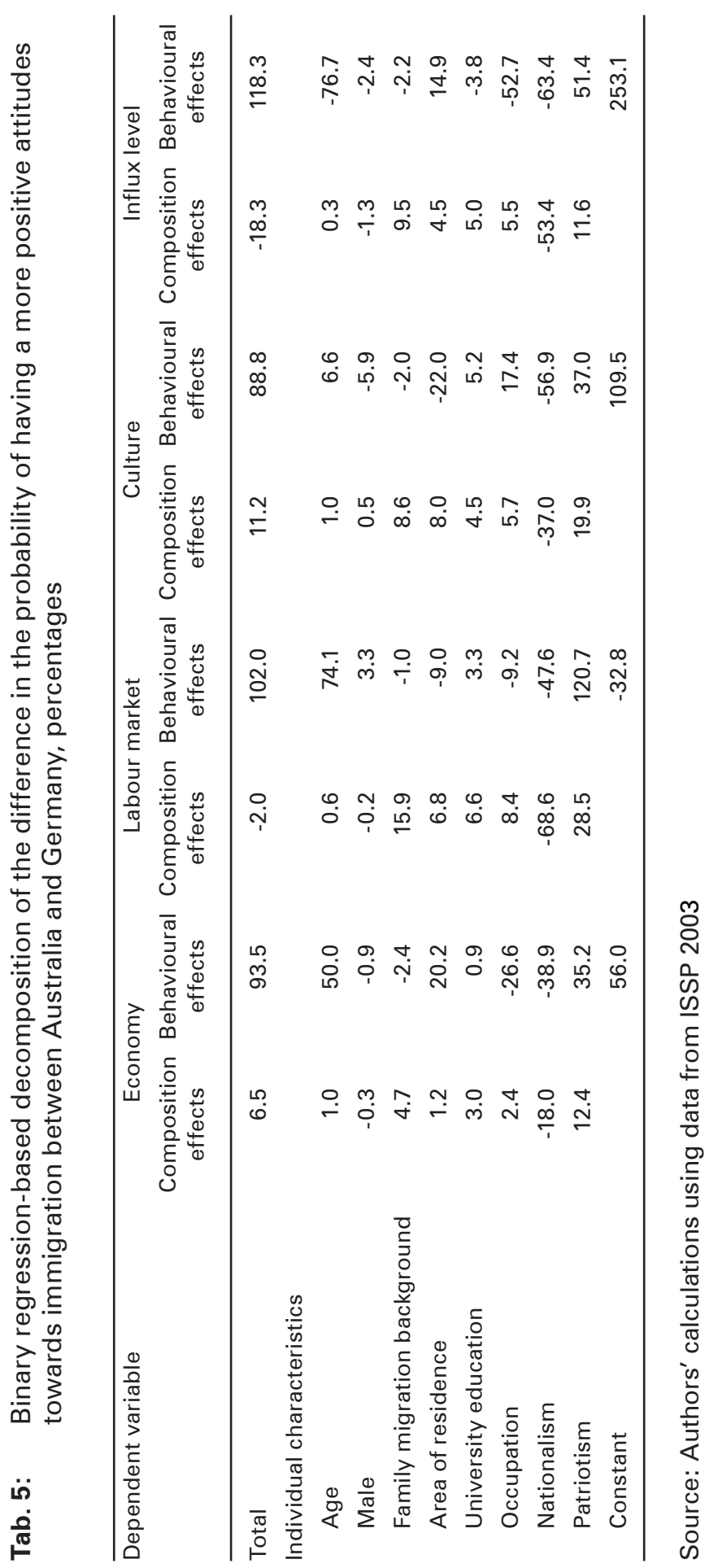




\section{$5 \quad$ Explaining differences in immigration attitudes between Australia and Germany}

Compared to Germans, Australians tend to hold more positive attitudes towards immigration across our four dimensions: national economy, labour market, culture and influx levels of immigration. Table 5 summarises the decomposition analysis of these attitudinal differences and displays the contribution of compositional and behavioural effects. A positive sign indicates a positive contribution of a particular factor to the difference in attitudes towards immigration between Australia and Germany. A negative sign points to an offsetting effect, that is, a contribution of a factor to reducing cross-national differences in the probability of holding positive attitudes towards immigration.

In the first row, Table 5 shows the total contribution of compositional effects (differentials in population composition) and behavioural effects (differentials in coefficients) to differences in attitudes, while the rows below contain the additive contributions of individual explanatory variables to these totals. The results indicate that behavioural effects represent the main source of the difference between Australia and Germany in the probability of being more positive toward immigration, whereas compositional effects account for a modest share. This finding is robust. It is persistent across our four measures of attitudes towards immigration. However, there are some variations in the contribution of behavioural effects across these measures of attitudes towards immigration. While behavioural effects contribute 89 percent to the difference in likelihood of having positive attitudes towards immigration from the perspective of national culture, they contribute over 118 percent when the perspective of preferred level of immigration influx is considered. This large share associated with the latter perspective indicates that, in the absence of counteracting compositional effects, the difference in shares of positive attitudes towards immigration between Australia and Germany would have been 18 percent larger.

The dominant role of behavioural responses in explaining the differences in attitudes towards immigration between Australians and Germans points to the importance of the national contexts in which these attitudes emerge. Specifically, coupled with other country-specific factors, we argue that the comprehensive immigration programme of Australia has played an important role in influencing the formation of positive attitudes towards immigration by facilitating the planned influx and settlement of foreigners as discussed in Section 2.1. In contrast, the lack of such a programme in Germany for most of the $20^{\text {th }}$ century is thought to be related to less positive views on the impacts of immigration. This significance of policy frameworks in explaining cross-national differences in attitudes towards immigration is consistent with recent evidence on the relationship between permissive policies and more positive attitudes in the context of greater approval of homosexuality (Kuntz et al. 2015).

Behavioural effects associated with patriotism, age composition and the constant term represent the main contributors to the difference in attitudes towards immigration between Australia and Germany. The effect associated with patriotism 
appears to explain more than 35 percent of this difference in each of the four attitudinal dimensions. This percentage is particularly large (121 percent) if we consider people's attitudes towards immigration concerning its impacts on the national labour market. The large contribution of behavioural effects of patriotism on the difference in attitudes towards immigration between the two countries appears to reflect that the positive association between being patriotic and having more favourable sentiments toward immigrants is stronger in Australia - as shown by the large and positive coefficient associated with patriotism in that country (Table 4). Australians seem to be more patriotic than Germans (see Table 2), and with Australia's commitment to immigration and multiculturalism, Australians with patriotic sentiments are more likely to support their country's policy and show greater acceptance of people with different cultural backgrounds.

Differences in behavioural effects associated with age also explain a significant share of the difference in attitudes towards immigration between Australia and Germany. They contribute between 6.6 percent and 74 percent of the difference of people's perceptions on the impacts of immigration on the national economy, labour market and culture. However, these effects appear to reduce the gap in the probability of being positive towards a greater influx of immigrants between Australians and Germans. This appears to be because Germans at young-adult ages tend to be more favourable towards an increase in immigration numbers than Australians, as is indicated by a larger positive coefficient of age on the probability of holding more positive views of greater immigration levels. The more positive attitudes towards immigration among young Germans might reflect the onset of changes to the country's immigration policy framework at the beginning of the $21^{\text {st }}$ century (see Suessmuth 2001). Specifically, the arguments for a change in policy - immigration as a remedy for future population decline, labour force shortages and population ageing - were more relevant to younger generations.

Behavioural effects associated to the regression constant represent another major contributor to the difference in attitudinal responses towards immigration between Australia and Germany. When the impacts on the national economy, culture and level of influx are considered, these effects appear to account for more than 50 percent of the difference. While the effects captured by the regression constant may represent the influence of a series of measurement errors and contextual factors not included in the regression models, they are also likely to represent structural differences in the perception of immigration between the Australian and German population, and hence to reflect the role of the contrasting immigration policy frameworks in the two countries. It appears that Australia has created a more favourable setting for positive attitudes towards immigration to emerge.

Balancing the behavioural effects of patriotism, age and the regression constant, there was a major offsetting individual effect associated with nationalism. In the absence of this effect, differences in the likelihood of displaying positive attitudes towards immigration between Australians and Germans would have been larger. Behavioural effects associated with nationalism appear to have reduced these differences by about 37 percent. The regression results suggest that these offsetting effects linked to nationalism reflect the negative influence that holding a nationalist 
disposition exerts on the probability of displaying more positive attitudes towards immigration, and their larger magnitude in Australia. That is, individuals with nationalist sentiments in Australia tend to be less positive towards immigration than their German counterparts. Hence, Germans with a nationalist disposition can be seen as less negative towards immigration, which diminishes the overall differences in the likelihood of displaying positive attitudes towards immigration. The stronger negative effect of nationalist sentiments on attitudes towards immigration in Australia might link to Australia's policy. The country's concepts of active recruitment and multiculturalism might foster more accentuated negative perceptions of immigration among people with nationalist beliefs.

\section{Conclusion}

In this paper, we have explored the relationship between immigration policy and attitudes towards immigration. We argue that a country's immigration policy framework plays an important role in shaping the national context in which attitudes towards immigration are formed, and hence it is likely to be a major driver underpinning cross-country differences in the perceived impact of immigration. To provide evidence for this argument, we investigated the factors underlying differences in attitudes towards immigration between Australia and Germany. To this end, we distinguished four dimensions of attitudes towards immigration that capture different but complementary perceptions of immigration. We thus defined four measures of attitudes towards immigration concerning the impact of immigration on (1) the national economy, (2) the labour market, (3) culture, and (4) the level of influx. We compared Australia and Germany because these countries established contrasting policy frameworks during the 1970s following a period of large-scale immigration in the post-war decades. Australia developed a proactive immigration programme, organising the intake and settlement of immigrants under a multicultural principle. This contrasts with the German policy framework, which focused on reducing the intake and stock of immigrants.

Our analysis of attitudes towards immigration in Australia and Germany revealed three findings. First, there are significant differences in attitudinal responses towards immigration between the two countries. People in Australia tend to be more positive towards immigration than people in Germany. This finding is consistent across the four dimensions in which we measured immigration, but Australians are markedly more positive about the impact immigration has on the national economy.

Second, our findings show a similar pattern of individual determinants of attitudes towards immigration in Australia and Germany. In both countries, people tend to be more favourable towards immigration if they have a migration background themselves, live in inner-city areas, hold a university degree, work in higher-skilled jobs and are less disposed to nationalist sentiments; while gender does not appear to have a significant influence. An unexpected finding was the effect of patriotism on influencing positive attitudes towards immigration. Most previous studies found that strong feelings of national identity are associated with less favourable attitudes 
towards immigration. In our models, only nationalism showed a negative effect, while the effect of patriotism was found to be positive. Both effects were larger in magnitude in Australia. A permissive immigration policy might encourage positive attitudes towards immigration among people with patriotic feelings who sympathise with their country's actions. However, if attachment to a country is associated with nationalist feelings of cultural superiority and opposition to ethnic diversity, a permissive immigration policy might stimulate negative perceptions of immigration.

Third, our results show that, rather than cross-national differences in population composition, differences in behavioural responses comprise the main factor explaining the more positive attitudes towards immigration found in Australia compared to Germany. Together with cross-national differences in the effects of age and patriotic sentiments, structural differences in the perception of immigration in Australia and Germany represent the main behavioural responses that shape more positive attitudes towards immigration in Australia. The Australian multicultural and skill-targeted policy framework has operated to create a more favourable context for the formation of positive attitudes towards immigration by shaping people's perception on the economic and socio-cultural impacts of immigration.

It should be noted, however, that the causal direction of the link between policy and attitudes likely goes both ways. Politicians and policy-makers generally respond to what they think the general public perceives as the right direction of policy. Furthermore, the study design (as an in-depth examination of the influence of immigration policy on different dimensions of attitudes towards immigration) did not allow a systematic testing of alternative explanations. It may be the case that other contextual factors influence the attitudinal differences between Australia and Germany to some extent. At the same time, our findings are in line with recent empirical research, strongly indicating that policy indeed shapes attitudes.

This link between policy and attitudes is of major concern regarding increasing global competition for migrant talent (Shachar 2006). A proactive immigration policy that offers a legal framework for immigration pathways and also provides a substantial support system for the social and economic settlement process of immigrants is an important mechanism for increasing the societal acceptance of immigrants by positively influencing the perception of the local population about the impacts of immigration on the local economy and culture. Policy not only sets out the legal pathways for entering and settling in a country, but plays a role in shaping a tolerant and permissive environment for immigration - an important factor for migrants when choosing a destination country (Paas/Halapuu 2011). At the same time, negative attitudes towards immigration, coupled with discrimination, low education and lack of self-confidence represent key barriers to the social and economic integration of immigrants (Constant et al. 2009).

With the new immigration act of 2005 , German policy-makers laid the foundation for major reforms towards a proactive immigration policy, targeting the admission of skilled migrants and improving the support for migrants' settlement processes. Future research could investigate whether attitudes towards immigration have changed as a reaction to this shift in policy. Such research could be based on data from the third round of the ISSP National Identity module, which was carried out in 2013. 


\section{References}

Bauer, Thomas K. et al. 2001: Immigration Policy, Assimilation of Immigrants, and Natives' Sentiments Towards Immigrants: Evidence from 12 OECD Countries. Working Paper No. 33. Center for Comparative Immigration Studies: UC San Diego.

Bauer, Thomas K.; Sinning, Mathias 2008: An extension of the Blinder-Oaxaca decomposition to non-linear models. In: Advances in Statistical Analysis 92,2: 197-206 [doi: 10.1007/s10182-008-0056-3].

Birrell, Bob 2009: Immigration policy in Australia. In: Nieuwenhuysen, John P.; Higley, John; Neerup, Stine (Eds.): Nations of Immigrants: Australia and the USA Compared. Cheltenham: Edward Elgar Publishing.

Blank, Thomas; Schmidt, Peter 2003: National identity in a united Germany: Nationalism or patriotism? An empirical test with representative data. In: Political Psychology 24,2: 289-312 [doi: 10.1111/0162-895X.00329].

Brenner, Jan; Fertig, Michael 2006: Identifying the determinants of attitudes towards immigrants: a structural cross-country analysis. In: IZA Discussion Paper 2306. Institute for the Study of Labor: Bonn.

Card, David et al. 2005: Understanding attitudes to immigration: The migration and minority module of the first European Social Survey. CReAM Discussion Paper 03/2005. Centre for Research and Analysis of Migration: University College London.

Castles, Stephen 2008: The Migratory Process: A Comparison of Australia and Germany. The Age of Migration $4^{\text {th }}$ Edition Website, Web-only Chapter [http://www.ageof-migration.com/uk/casestudies/11.1.pdf].

Castles, Stephen; Miller, Mark J. 2008: The Age of Migration: International Population Movements in the Modern World. New York: Palgrave.

Ceobanu, Alin M.; Escandell, Xavier 2010: Comparative analyses of public attitudes toward immigrants and immigration using multinational survey data: A review of theories and research. In: Annual Review of Sociology 36: 309-328 [doi: 10.1146/annurev. soc.012809.102651].

Constant, Amelie F. et al. 2009: Attitudes towards immigrants, other integration barriers, and their veracity. In: International Journal of Manpower 30,1/2: 5-14 [doi: 10.1108/01437720910948357].

Davidov, Eldad; Meuleman, Bart 2012: Explaining attitudes towards immigration policies in European countries: The role of human values. In: Journal of Ethnic and Migration Studies 38,5: 757-775 [doi: 10.1080/1369183X.2012.667985].

Davidov, Eldad et al. 2008: Values and support for immigration: A cross-country comparison. In: European Sociological Review 24,5: 583-599 [doi: 10.1093/esr/jcn020].

DIMA 2010: Overview of Skilled Migration to Australia. Canberra: Department of Immigration and Citizenship. Commonwealth of Australia [http://www.immi.gov.au/media/ fact-sheets/24overview_skilled.htm].

Fienberg, Stephen 1980: The analysis of cross-classified categorical data, 2 edn. Cambridge, MA: MIT Press.

Gang, Ira et al. 2002: Economic strain, ethnic concentration and attitudes towards foreigners in the European Union. IZA Discussion Paper 578: Institute for the Study of Labor: Bonn. 
Godenau, Dirk et al. 2012: Labour Market Integration and Public Perceptions of Immigrants: A Comparison between Germany and Spain During the Economic Crisis. In: Comparative Population Studies - Zeitschrift für Bevölkerungswissenschaft 37,1-2 [doi: 10.4232/10.CPoS-2011-1-3de].

Hainmueller, Jens; Hiscox, Michael J. 2007: Educated preferences: Explaining attitudes toward immigration in Europe. In: International Organization 61,02: 399-442 [doi: 10.1017/S0020818307070142].

Harkness, Janet et al. 2004: Survey Questionnaire Translation and Assessment. In: Presser, Stanley et al. (Eds.): Methods for testing and evaluating survey questionnaires. New York: Wiley: 453-473.

Hayes, Bernadette C.; Dowds, Lizanne 2006: Social contact, cultural marginality or economic self-interest? Attitudes towards immigrants in Northern Ireland. In: Journal of Ethnic and Migration Studies 32,3: 455-476 [doi: 10.1080/13691830600554890].

Hugo, Graeme 2004: A new paradigm of international migration: implications for migration policy and planning in Australia. Research Paper No. 10 2003-04. Information, Analysis and Advice for the Parliament, Department of Parliamentary Services, Parliamentary Library. Canberra: Commonwealth of Australia.

Hugo, Graeme 2009: Flows of immigrants 1993-2008: Australia. In: Nieuwenhuysen, John P.; Higley, John; Neerup, Stine (Eds.): Nations of Immigrants: Australia and the USA Compared. Cheltenham: Edward Elgar Publishing.

ISSP Research Group 2005: International Social Survey Programme: National Identity II - ISSP 2003. Cologne: GESIS Data Archive.

Jeong, Hoi OK 2013: Do National Feelings Influence Public Attitudes towards Immigration? In: Journal of Ethnic and Migration Studies 39,9: 1461-1477 [doi: 10.1080/1369183X.2013.815428].

Joppke, Christian 1999: Immigration and the Nation-State: The United States, Germany, and Great Britain. New York: Oxford University Press.

Jupp, James 2007: From White Australia to Woomera: The Story of Australian Immigration. Cambridge: Cambridge University Press.

Kuntz, Anabel et al. 2015: Human values, legal regulation, and approval of homosexuality in Europe: A cross-country comparison. In: European Journal of Social Psychology 45,1: 120-134 [doi: 10.1002/ejsp.2068].

Levy, Danie/ C. 2002: The Transformation of Germany's Ethno-cultural Idiom: The Case of Ethnic German Immigrants. In: Levy, Danie/ C.; Weiss, Yfaat (Eds.): Challenging Ethnic Citizenship: German and Israeli Perspectives on Immigration. New York: Berghahn Books.

Madden, David 2010: Gender differences in mental well-being: a decomposition analysis. In: Social indicators research 99,1: 101-114 [doi: 10.1007/s11205-009-9569-8].

Malchow-Møller, Nikolaj et al. 2009: Explaining cross-country differences in attitudes towards immigration in the EU-15. In: Social indicators research 91,3: 371-390 [doi: 10.1007/s11205-008-9341-5].

Markus, Andrew et al. 2009: Australia's Immigration Revolution. Crows Nest NSW: Allen \& Unwin.

Mayda, Anna Maria 2006: Who is against immigration? A cross-country investigation of individual attitudes toward immigrants. In: The Review of Economics and Statistics 88,3: 510-530 [doi: 10.1162/rest.88.3.510].

Meier-Braun, Karl-Heinz 2002: Deutschland, Einwanderungsland. Frankfurt am Main: Suhrkamp. 
Meuleman, Bart et al. 2009: Changing attitudes toward immigration in Europe, 20022007: A dynamic group conflict theory approach. In: Social Science Research 38,2: 352-365 [doi: 10.1016/j.ssresearch.2008.09.006].

Meyers, Eytan 2007: International Immigration Policy: A Theoretical and Comparative Analysis. New York: Palgrave Macmillan.

Mummendey, Amelie et al. 2001: Nationalism and patriotism: National identification and out-group rejection. In: British Journal of Social Psychology 40,2: 159-172 [doi: 10.1348/014466601164740].

O'Connell, Michael 2011: How do high-skilled natives view high-skilled immigrants? A test of trade theory predictions. In: European Journal of Political Economy 27,2: 230240 [doi: 10.1016/j.ejpoleco.2010.11.002].

O'Rourke, Kevin H.; Sinnott, Richard 2006: The determinants of individual attitudes towards immigration. In: European Journal of Political Economy 22,4: 838-861 [doi: 10.1016/j.ejpoleco.2005.10.005].

Paas, Tiiu; Halapuu, Vivika 2011: Competition for People as Drivers of Future Economic Growth: European People's Attitudes Towards Migration. In: Discussions on Estonian Economic Policy 2/2011 [doi: 10.2139/ssrn.1998058].

Rustenbach, Elisa 2010: Sources of Negative Attitudes Toward Immigrants in Europe: A Multi-Level Analysis. In: International migration review 44,1: 53-77 [doi: 10.1111/j.17477379.2009.00798.x].

Scheve, Kenneth F.; Slaughter, Matthew J. 2001: Labor market competition and individual preferences over immigration policy. In: Review of Economics and Statistics 83,1: 133-145 [doi: 10.1162/003465301750160108].

Schlueter, Elmar et al. 2013: Immigrant integration policies and perceived group threat: a multilevel study of 27 Western and Eastern European countries. In: Social Science Research 42,3: 670-682 [doi: 10.1016/j.ssresearch.2012.12.001].

Scholz, Evi et al. 2005: ISSP Study Monitoring 2003 - Report to the ISSP Gerneral Assembly on monitoring work undertaken for the ISSP. ZUMA Methodenbericht. Mannheim: Leibniz Institute for the Social Sciences.

Shachar, Ayelet 2006: The Race for Talent: Highly Skilled Migrants and Competitive Immigration Regimes. NYU Law Review 81: 148-206.

Sides, John; Citrin, Jack 2007: European opinion about immigration: The role of identities, interests and information. In: British Journal of Political Science 37,3: 477 [doi: 10.1017/S0007123407000257].

Süssmuth, Rita 2001: Zuwanderung gestalten - Integration fördern. Bericht der Unabhängigen Kommission "Zuwanderung". Berlin: Bundesministerium des Innern.

The World Bank 2015: World Development Indicators - GDP growth (annual \%).

UNDESA 2006: Trends in Total Migrant Stock: The 2005 Revision. edited by P.D. United Nations Department of Economic and Social Affairs. New York: United Nations.

Wilson, Thomas C. 1991: Urbanism, migration, and tolerance: A reassessment. American Sociological Review 56,1: 117-123.

Yun, Myeong-Su 2008: Identification problem and detailed Oaxaca decomposition: a general solution and inference. In: Journal of economic and social measurement 33,1 : 27-38.

Zimmermann, Klaus F. et al. 2007: Immigration policy and the labor market: the German experience and lessons for Europe. Berlin: Springer. 
Philipp Ueffing $(\triangle)$, Dr. Francisco Rowe. Queensland Centre for Population Research, The University of Queensland. Australia.

E-mail: p.ueffing@uq.edu.au,f.rowegonzalez@uq.edu.au

URL: https://www.gpem.uq.edu.au/philipp-ueffing https://www.gpem.uq.edu.au/francisco-rowe

Prof. Dr. Clara H. Mulder. University of Groningen, Faculty of Spatial Sciences, Department of Demography. Groningen, The Netherlands. E-mail: c.h.mulder@rug.nl URL: http://www.rug.nl/staff/c.h.mulder/ 


\section{Appendix}

Tab. A1: Definition of exploratory variables

\begin{tabular}{|c|c|}
\hline Variable & Definition \\
\hline Sex & Sex of respondent \\
\hline Male & Male \\
\hline Female & Female \\
\hline Migration background & Parents citizens of country at time of respondent's birth \\
\hline No foreign parent & Neither parent citizen of another country at time of births \\
\hline At least one foreign parent & At least one parent citizen of another country at time of birth \\
\hline Area of residence & Self-assessed area of residence \\
\hline Village & AUS: Farm or small country town $(<10,000)$; GER: Farm or village \\
\hline Town & $\begin{array}{l}\text { AUS: Larger country town }(>10,000) \text { or large town }(>25,000) \text {; GER: } \\
\text { Small- or medium-sized city }\end{array}$ \\
\hline Outer area major city & $\begin{array}{l}\text { AUS: Outer metropolitan area of major city }(>100,000) \text {; GER: Fringe } \\
\text { or suburbs of major city }\end{array}$ \\
\hline Inner area major city & $\begin{array}{l}\text { AUS: Inner metropolitan area of major city }(>100,000) \text {; GER: Major } \\
\text { city }\end{array}$ \\
\hline University education & Highest educational level \\
\hline No university degree & No university degree completed \\
\hline University degree & University degree completed (Bachelor's and above) \\
\hline Occupation & Occupation by ISCO88 classifications \\
\hline Elementary occupations & Elementary occupations (ISCO 1) \\
\hline Manual occupations & $\begin{array}{l}\text { Plant and machine operator and assemblers, Craft and related } \\
\text { trades workers, Skilled agricultural and fishery workers, Service } \\
\text { workers and shop market sales workers, Clerks (ISCO 2) }\end{array}$ \\
\hline Technical occupations & Technicians and associate professionals (ISCO 3 ) \\
\hline Professional occupations & Professionals (ISCO 4) \\
\hline Managerial occupations & Legislators, senior officials and managers \\
\hline Age & Age in years \\
\hline Age squared & Age squared \\
\hline \multirow[t]{2}{*}{ Nationalism } & Person's belief that his/her country is better than others. \\
\hline & $\begin{array}{l}\text { Constructed as index from three ISSP questions (Cronbach's } \\
\text { Alpha = 0.76), each measured on a five point scale from "strongly } \\
\text { disagree" to "strongly agree". Coded in the way that higher value } \\
\text { depicts stronger nationalist feelings. Questions: } \\
\text { "Generally speaking, [Country] is a better country than } \\
\text { most other countries" } \\
\text { "I would rather be a citizen of [Country] than of any other } \\
\text { country in the world" } \\
\text { "The world would be a better place if people from other } \\
\text { countries were more like [Country nationality]" }\end{array}$ \\
\hline
\end{tabular}


Tab. A1: Continuation

\begin{tabular}{ll}
\hline Variable & Definition \\
\hline Patriotism & Person's pride in being a member of the own nation without notion \\
of superiority over other countries. \\
Constructed as index from three ISSP questions (Cronbach's Alpha \\
$=0.72$ ), each measured on a four point scale from "not proud at \\
all" to "very proud". Coded in the way that higher value depicts \\
stronger patriotic feelings. Questions: \\
"How proud are you of [Country] in each of the following?" \\
- "ICountry's] economic achievements? \\
- Its scientific and technological achievements? \\
- Its achievements in sports?
\end{tabular}

Source: ISSP 2003 
464 - Philipp Ueffing, Francisco Rowe, Clara H. Mulder

Tab. A2: Measures of attitudes towards immigration - Response distribution over original answer categories

\begin{tabular}{|c|c|c|c|c|c|c|c|c|}
\hline \multirow{2}{*}{$\begin{array}{l}\text { Response } \\
\text { Category }^{1}\end{array}$} & \multicolumn{2}{|c|}{ Economy } & \multicolumn{2}{|c|}{ Labour Market } & \multicolumn{2}{|c|}{ Culture } & \multicolumn{2}{|c|}{ Influx } \\
\hline & Australia & Germany & Australia & Germany & Australia & Germany & Australia & Germany \\
\hline 1 & 0.01 & 0.09 & 0.06 & 0.13 & 0.01 & 0.06 & 0.18 & 0.46 \\
\hline 2 & 0.07 & 0.26 & 0.19 & 0.30 & 0.07 & 0.14 & 0.21 & 0.26 \\
\hline 3 & 0.21 & 0.38 & 0.25 & 0.27 & 0.17 & 0.25 & 0.38 & 0.23 \\
\hline 4 & 0.60 & 0.26 & 0.42 & 0.22 & 0.58 & 0.49 & 0.17 & 0.04 \\
\hline 5 & 0.10 & 0.01 & 0.08 & 0.08 & 0.17 & 0.07 & 0.06 & 0.01 \\
\hline
\end{tabular}

1 Recoded so that categories 1 and 2 correspond to negative attitudes towards immigration, 3 to neutral, and 4 and 5 to positive attitudes towards immigration

Source: Authors' calculations using data from ISSP 2003 


\section{Comparative Population Studies}

WWW.comparativepopulationstudies.de

ISSN: 1869-8980 (Print) - 1869-8999 (Internet)

Published by / Herausgegeben von

Prof. Dr. Norbert F. Schneider

Federal Institute for Population Research

D-65180 Wiesbaden / Germany

\section{Managing Editor /}

Verantwortlicher Redakteur

Frank Swiaczny

\section{Assistant Managing Editor /}

\section{Stellvertretende Redakteurin}

Katrin Schiefer

\section{Copy Editor (German) /}

Lektorat (deutsch)

Dr. Evelyn Grünheid

\section{Layout / Satz}

Beatriz Feiler-Fuchs

E-mail:cpos@bib.bund.de

\section{Scientific Advisory Board /}

Wissenschaftlicher Beirat

Paul Gans (Mannheim)

Johannes Huinink (Bremen)

Michaela Kreyenfeld (Rostock)

Marc Luy (Wien)

Clara H. Mulder (Groningen)

Notburga Ott (Bochum)

Peter Preisendörfer (Mainz)

Zsolt Spéder (Budapest)
Board of Reviewers / Gutachterbeirat Martin Abraham (Erlangen)

Laura Bernardi (Lausanne)

Hansjörg Bucher (Bonn)

Claudia Diehl (Konstanz)

Andreas Diekmann (Zürich)

Gabriele Doblhammer-Reiter (Rostock)

Jürgen Dorbritz (Wiesbaden)

Anette Eva Fasang (Berlin)

E.-Jürgen Flöthmann (Bielefeld)

Alexia Fürnkranz-Prskawetz (Wien)

Beat Fux (Salzburg)

Joshua Goldstein (Berkeley)

Karsten Hank (Köln)

Sonja Haug (Regensburg)

Hill Kulu (Liverpool)

Aart C. Liefbroer (Den Haag)

Kurt Lüscher (Konstanz)

Emma Lundholm (Umeå)

Nadja Milewski (Rostock)

Dimiter Philipov (Wien)

Roland Rau (Rostock)

Tomáš Sobotka (Wien)

Jeroen Spijker (Barcelona)

Olivier Thévenon (Paris)

Helga de Valk (Brussel)

Heike Trappe (Rostock)

Michael Wagner (Köln) 